\title{
A INTERNET BANKING NO BRASIL, NA AMÉRICA LATINA E NA EUROPA
}

\author{
Manuel Martin Pino Estrada
}

\begin{abstract}
RESUMO
Com o advento do Internet banking as operações financeiras, os pagamentos, as operações bancárias tradicionais como as transferências de dinheiro entre contas, descontos, duplicatas e faturas passam a ser eletrônicas, circulando pelo meio digital são realizadas mais eficientemente as tarefas que as pessoas faziam por si. O propósito do presente trabalho é mostrar os diferentes aspectos da Internet Banking, sendo um dos motores do desenvolvimento do comércio eletrônico, considerando o mundo globalizado no qual nós vivemos, além de ver como o Brasil, alguns países da América Latina e da União Européia estão enfrentando legalmente este fenômeno, que continua aumentando o número de usuários dia após dia.
\end{abstract}

Palavras-chaves: Internet banking; operações financeiras; comércio eletrônico

The Internet Banking in Brazil, Latin America and Europe

\begin{abstract}
With the advent of the Internet banking the financial operations, the payments, the traditional banking transactions as the money transferences enters accounts, discountings, duplicates and invoices start to be electronic, circulating for the digital way wich are more efficiently carried through the tasks that the people made for itself. The intention of the present work is to show the differents aspects of the Internet banking, being one of the engines electronic commerce's development, considering the global world which we live, besides seeing as Brazil, some countries of Latin America and of the European Union they are legally facing this phenomenon, that after continues increasing the users numbers day by day.
\end{abstract}

Keywords:. Internet banking; financial operations; electronic commerce 


\section{Introdução}

A informática marcou o fim do século passado e agora faz parte do nosso quotidiano. Os computadores estão presentes nos nossos relógios até nos fogões que aquecem a nossa comida, passando pelos freios dos carros, telefones, celulares, dentre outros.

A informática não se reduz só à fabricação de aparelhos, também se estende na transmissão de notícias, troca de dados e informações, além do estabelecimento de novos canais de comunicação entre as pessoas, propiciando a criação de uma nova maneira de fazer negócios.

Com o comércio eletrônico a Internet traz a vitrine do comerciante até o consumidor, sem que este precise sair de sua casa ou do seu escritório para vê-la. Ao mesmo tempo o comerciante não precisa mais de um estabelecimento físico, passando a ter um estabelecimento virtual. Antigamente ele visitava a casa das pessoas na zona rural ou nos bairros afastados, levando mercadorias de pequeno porte, e imagens ou amostras de outras que entregaria quando encomendadas pelo comprador interessado.

Com o comércio eletrônico este costume se mantém, porém, com outros meios.

Com o advento do Internet banking as operações financeiras, os pagamentos, as operações bancárias tradicionais como as transferências de dinheiro entre contas, descontos, duplicatas e faturas passam a ser eletrônicas, circulando pelo meio digital são realizadas mais eficientemente as tarefas que as pessoas faziam por si.

O propósito do presente trabalho é mostrar os diferentes aspectos da Internet Banking, sendo um dos motores do desenvolvimento do comércio eletrônico, considerando o mundo globalizado no qual nós vivemos, além de ver como o Brasil, alguns países da América Latina e da União Européia estão enfrentando legalmente este fenômeno, que continua aumentando o número de usuários dia após dia. 


\section{Conceito de Internet Banking}

Com a chegada dos meio informáticos começou a existir uma propagação de operações bancárias, dispensando-se os terminais bancários, nascendo o home banking ou office banking, que permite a realização de negócios por meio de sistemas oferecidos pela instituição bancária a computadores de seus clientes equipados com mecanismos como o modem para acessar a rede privada do banco.

Sob o ponto de vista técnico o home banking (ou office banking) não se confunde com internet banking, na medida em que neste último, o acesso à rede bancária (que ocorre pela Internet) dispensa a prévia instalação de sistemas próprios dos bancos nos computadores de seus clientes.

O internet banking representa uma nova modalidade de comércio eletrônico, pela qual o cliente, valendo-se da internet tem acesso a vários serviços bancários para a realização de negócios e contratos eletrônicos, os quais, por sua vez, são definidos como contratos celebrados por meio de programas de computador ou aparelhos com tais programas, dispensando-se a assinatura codificada ou senha ${ }^{1}$.

\section{Vantagens das operações bancárias na Internet}

a) diminuição de custos fixos de manutenção de uma agência bancária, especificamente nas despesas de pessoal;

\footnotetext{
${ }^{1}$ GOMES, Alessandra Aparecida Calvoso. Operações bancárias via Internet (Internet banking) no Brasil e suas repercussões jurídicas. In Revista dos Tribunais, vol. 816, outubro de 2003.
} 
b) desburocratização de serviços, facilitando a vida do cliente, dispensando sua presença física no estabelecimento, evitando filas e perda de tempo realizando operações bancárias;

c) o alcance geográfico, pelo fato da Internet atingir o mundo todo, podendo fornecer serviços em grande escala;

d) diminuição de riscos de assaltos, porque há um menor movimento de pessoas, moeda e serviços nas agências bancárias

\section{A realidade do internet banking brasileiro}

A Pesquisa anual da e-bit revela o crescimento da utilização dos serviços de Internet Banking pelos e-consumidores e o que os bancos ainda precisam fazer para melhorar seu serviço pela

Internet.

A utilização dos serviços de Internet Banking cresce constantemente no Brasil. Esse é um dos fatos revelados pela edição de 2003 da pesquisa anual realizada pela e-bit, empresa de pesquisa e marketing.

"O setor bancário brasileiro é um dos mais modernos do mundo e isso colaborou para o desenvolvimento do Internet Banking no país. Hoje, o Banco do Brasil, que é o banco nacional com mais clientes cadastrados no canal virtual, está entre os cinco maiores da Internet no mundo", revela Fabiana Curi Yazbek, diretora de produtos da e-bit.

Além disso, outro fato revelado pelo estudo é que, grande parte dos usuários de Internet Banking utilizam o serviço com muita frequência. Entre os entrevistados, 32\% acessam o banco pela Internet todos os dias, enquanto 30\% acessa entre 3 e 5 vezes por semana. Em relação às funções mais acessadas e utilizadas, a consulta de saldo/extrato vem em primeiro lugar. Hoje, 79\% dos usuários de Internet Banking revelam utilizar frequentemente essa função. Em segundo lugar ficam os pagamentos - utilizado por $60 \%$ - e as transferências e Doc's - usadas por $44 \%$. 
Mesmo assim, a pesquisa revela que ainda há muito o que melhorar. Mais de $10 \%$ dos entrevistados revelou que utilizaria mais o serviço se alguém o ensinasse a usar. Além disso, 46\% revelou que sente falta de atendimento online e $42 \%$ gostariam também de um canal de contato direto com seu gerente por e-mail.

"Isso também pode representar que, se a navegação dos sites bancários fosse mais fácil e intuitiva, os clientes não teriam esse tipo de dificuldade. Estudos de Usabilidade com os usuários desse site podem trazer uma grande quantidade de subsídios para tornar os sites mais simples e completos para todos", completa Fabiana

Outro ponto que deve ser observado pelos bancos é a segurança, ou a falta dela. Para 28\% dos entrevistados, isso ainda é o principal problema na hora de acessar o site do banco.

Segundo a pesquisa, a redução nas tarifas (17\%) e programas de incentivo ou milhas (11\%) também podem contribuir para uma maior utilização do canal.

A edição de 2003 da pesquisa anual da e-bit sobre a utilização dos serviços de Internet Banking no Brasil foi realizada em parceria com a Fundação Getúlio Vargas (FGV) e a Revista Business Standard. Esse ano, a pesquisa contou com mais de 2 mil respostas, principalmente de consumidores de lojas virtuais. Ou seja, pessoas que estão acostumadas a usar a Internet para adquirir produtos e serviços ${ }^{2}$.

\section{As atividades bancárias na internet}

As atividades bancárias consistem, em síntese, em intermediar dinheiro, ou seja, os bancos captam esse bem no mercado e o repassam. Nessa intermediação eles são remunerados pelo spread (diferença entre o valor do dinheiro na captação e no repasse, simbolizado na taxa de juros).

Os bancos atualmente são instituições multifuncionais, dedicando-se a uma variedade de outras atividades.

\footnotetext{
${ }^{2}$ www.ebitempresa.com.br/index_ebitinforma.htm 
A legislação brasileira acompanhou a evolução dessas atividades, primeiramente com a Lei 4.595 de 31/12/1964, dispondo sobre a divisão entre bancos comerciais e bancos de investimento. Posteriormente, em 20/09/98 foi editada a Resolução 1524 do Bacen (Banco do Brasil), permitindo a operação de bancos múltiplos ${ }^{3}$.

Entre os serviços que mais se refletem na vida dos clientes usuários de internet banking, destacam-se consultas a saldos, obtenção de extratos, transferências de valores entre contas ou de uma pessoa a outra, pagamentos (chamados de $e$-cash) e abertura de conta.

O Conselho Monetário Nacional aprovou a Resolução 2.817 de 22.02.2001, a qual viabiliza, entre outras providências, a abertura de contas exclusivamente por meio eletrônico em instituições financeiras ou em entidades autorizadas a funcionar pelo Banco Central do Brasil.

Para fins de aplicação da referida norma, meios eletrônicos compreendem a internet, os terminais de auto-atendimento, o telefone e outros meios de comunicação a distância disponíveis pela instituição bancária para fins de relacionamento com seus clientes (art. $1^{\circ}$, \& $1^{\circ}$ ).

Quanto à questão da abertura de conta bancária, cumpre destacar que há uma série de formalidades pertinentes à conferência de documentos originais e à elaboração de declaração de responsabilidade previstas em normativos do Bacen. A resolução 2.817/2001 desburocratiza várias dessas exigências, mas de outro lado, permite que as instituições requeiram, a seu critério, alguns documentos dos clientes. Para confirmar os dados, o banco irá comparar as informações fornecidas por meio eletrônico perante a instituição tradicional onde o cliente é titular da conta corrente ${ }^{4}$.

Por meio desta norma as instituições financeiras que disponibilizarem meios eletrônicos de relacionamento com qualquer tipo de cliente devem cumprir alguns requisitos ${ }^{5}$ :

\footnotetext{
${ }^{3}$ www.febraban.org.br

${ }^{4}$ Resolução 2.025/93 do Bacen

${ }^{5}$ Art. $2^{\circ}$ da Resolução 2.025/93 do Bacen
} 
1) fazer constar de forma clara e precisa: a) sua condição de instituição financeira ou autorizadas a funcionar pelo Bacen; b) sua denominação social; c) os números de telefones de atendimento, que devem, no mínimo, atender entre 8 e 18 horas nos dias úteis; d) o endereço eletrônico da página da Internet e do correio eletrônico, quando for o caso; e) relação dos servidores tarifados com os respectivos valores;

2) oferecer nas página da Internet instrumentos de envio de mensagens eletrônicas que devem ter seu recebimento confirmado e ser respondidas no prazo máximo de 5 dias e

3) controlar o sigilo, a segurança e monitorar as movimentações na conta dos clientes.

\subsection{Políticas de segurança nas operações bancárias na internet}

1) Política de segurança física, que consiste na implementação nas instalações físicas dos sistemas e equipamentos de informática empregados para a internet banking, como a escolha de um local adequado, afastado de áreas públicas, com sistemas de prevenção e combate à falta de energia elétrica, incêndio, processamentos alternativos e cópias dos processamentos.

2) Política de segurança lógica, compreendendo a proteção dos bancos de dados contra vírus informáticos, cuidando o armazenamento e manutenção dos arquivos, gerenciamento de risco, etc.

Estas duas políticas visam evitar que intrusos acessem bases de dados relativos às transações bancárias. Existem meios para tais como:

a) o emprego da certificação digital e criptografia: o certificado digital ou eletrônico é um arquivo de computador que identifica o seu usuário para outra pessoa ou para outro computador, com a finalidade de garantir a autenticidade, privacidade e inviolabilidade da comunicação. Este sistema executa a criptografia, que é o processo de codificar informações, de modo que apenas o destinatário pretendido da informação possa decodificá-las. 
b) o uso das senhas ou a biometria, que é o método de identificação por aspectos físicos, como a íris, impressão digital ou voz .

A Medida Provisória 2200-2 de 24 de agosto de 2001 estabelece o uso de sistema de segurança baseado em criptografia assimétrica, instituído pela Infra-estrutura de Chaves Públicas do Brasil (ICP-Brasil), que é uma organização composta por uma autoridade gestora de políticas (Comitê Gestor, vinculado à Casa Civil da Presidência da República) e por uma cadeia de Autoridades Certificadoras (AC) que são as responsáveis pela emissão dos certificados eletrônicos, tomando providências para estabelecer a identidade das pessoas ou organizações solicitantes do certificado.

Outra forma de prevenção de danos aos clientes do Internet banking é a política de divulgação de dicas pelos bancos, como trocar senha periodicamente, manter o antivírus atualizado, não realizar operações em equipamentos públicos e não abrir arquivos de origem desconhecida ${ }^{7}$.

\section{A validade jurídica do documento eletrônico}

A validade jurídica do documento eletrônico também reflete na segurança dos negócios realizados via internet banking, por facilitar seu uso como instrumento de prova.

Segundo o Projeto de Lei 4.906/2001 o documento eletrônico é a informação gerada, enviada, recebida, armazenada ou comunicada por meios eletrônicos, ópticos, optoeletrônicos ou similares.

O art. 333, I e II do Código de Processo Civil diz que a prova da existência do documento é ônus de quem o invoca em favor próprio. Além disso, nosso ordenamento traz como regra geral

\footnotetext{
${ }^{6}$ Op.cit. p.5

${ }^{7}$ www.santander.com.br
} 
a liberdade na utilização dos diversos meios de prova previstos ou não na lei (art. 322 do CPC), porém há exceções como o art. 401 do CPC onde a prova oral não pode ser admitida para contratos acima de dez salários mínimos.

Essa matéria vem tratada na Medida Provisória 2.200/2001, a qual, contudo, não impõe a utilização da certificação digital para fins de validade de documentos emitidos pela via eletrônica. Essa norma atribui presunção relativa de autenticidade às assinaturas digitais contidas em documento certificado eletronicamente por uma autoridade certificadora credenciada ao Comitê Gestor da ICP - Brasil (art. 10, parágrafo $1^{\circ}$ ).

O art. 225 do Novo Código Civil (Lei 10.406 de 2002) quanto ao valor probatório do documento eletrônico estabelece ainda, que as reproduções eletrônicas fazem prova plena dos fatos nelas tratados, se não for impugnada a exatidão pela outra parte.

\section{As operações bancárias na internet no Código de Defesa do Consumidor}

Existe uma questão polêmica sobre se o Código de Defesa do Consumidor se aplicaria nas relações bancárias.

Os bancos, como todo estabelecimento comercial, visam o lucro.

A existência de uma relação de consumo é encontrada quando se faz o nexo entre a definição legal de consumidor e de fornecedor de serviços. Desta forma o contrato de sérvios entre banco e cliente seria uma relação de consumo desde que se concretizem os elementos dos artigos $2^{\circ}$ e $3^{\circ}$ do CDC.

Art. $2^{\circ}$ : Consumidor é toda pessoa física ou jurídica que adquire ou utiliza produto ou serviço como destinatário final.

Parágrafo único: Equipara-se a consumidor a coletividade de pessoas, ainda que indetermináveis, que haja intervindo nas relações de consumo. 
Art. $3^{\text {o: }}$ Fornecedor é toda pessoa física ou jurídica, pública ou privada, nacional ou estrangeira, bem como os entes despersonalizados, que desenvolvem atividades de produção, montagem, criação, construção, transformação, importação, exportação, distribuição ou comercialização de produtos ou prestação de serviços.

Parágrafo $1^{\text {o }}$ é qualquer bem, móvel ou imóvel, material ou imaterial.

Parágrafo $2^{\circ}$ : Serviço é qualquer atividade fornecida no mercado de consumo, mediante remuneração, inclusive as de natureza bancária, financeira, de crédito e securitária, salvo a decorrentes das relações de caráter trabalhista.

Esta discussão começou pela edição da Lei 8078/90, quando se argumentou que não se poderia aceitar sua vigência nos contratos bancários, pois não seriam esses do consumo. Tal argumento se baseava no fato de que o dinheiro não podia consumir-se, portanto não haveria relação de consumo. Mas no art. 86 (antigo 51 do Código Civil de 1916) o dinheiro é um bem consumível, portanto bancário de que não pode existir relação de consumo torna-se vazio.

Também o art. $3^{\circ}$ parágrafo $2^{\circ}$ do CDC, para incluir as atividades bancárias como serviços fornecedores, usou o conectivo “inclusive”, deixando claro que normalmente não as abrangeria.

Já Arnoldo Wald aponta que o consumidor é aquele que usa o serviço com vista a satisfazer uma necessidade pessoal sem o objetivo de lucro. Isto implica que as pessoas que procuram o lucro não poderiam ser considerados consumidores.

De uma maneira geral, a doutrina e jurisprudência vêm orientando-se pela aplicação da lei consumerista às relações bancárias.

Mesmo assim, tal entendimento ainda não está pacificado, considerando que tramita perante o Supremo Tribunal Federal a Ação Direta de Inconstitucionalidade $\mathrm{n}^{0}$ 2.591, que tem como argumento principal à alegação de que as atividades bancárias fogem à natureza das relações de consumo, sendo o Código de Defesa do Consumidor uma lei ordinária, não poderia dispor quaisquer encargos e obrigações ao Sistema Financeiro Nacional, uma vez que a Constituição Federal dispõe, em seu artigo 192, II e IV, que caberá a Lei Complementar regular a matéria; que o conteúdo e alcance dos dispositivos legais acima citados já foram definidos pelo Supremo Tribunal Federal na ADIn n 4; haver, na Constituição Federal, distinção implícita entre 
consumidor e cliente de instituição financeira; que o código de defesa do consumidor, ao alcançar os agentes do Sistema Financeiro Nacional, estaria violando o princípio do devido processo legal, contido no artigo $5^{\circ}$, LIV, da Constituição Federal; o texto taxado de inconstitucional viola o princípio da proporcionalidade e da razoabilidade; não se pode confundir instituições do sistema financeiro nacional com os demais fornecedores, porque aqueles não podem garantir a boa qualidade de sua mercadoria, que é a moeda, e tampouco pode exigir-se que estas instituições concedam crédito a todas as pessoas; a inadequação da aplicação do Código de Defesa do Consumidor às instituições integrantes do Sistema Financeiro Nacional, que poderia se dar, por exemplo, por meio da análise dos artigos $20, \S 2^{\circ}, 21,23,35,6^{\circ}$, inciso $\mathrm{V}, 51, \S 1^{\circ}$, inciso III, e 117 do CDC; caberia à espécie, para suspender da ordem jurídica o texto legal taxado de inconstitucional (parte final do $\S 2^{\circ}$ do artigo $3^{\circ}$ do CDC), a concessão de liminar, por razões de conveniência ${ }^{8}$.

Desta forma, não se pode admitir que somente alguns segmentos da economia nacional fiquem à margem dessa evolução legislativa, como no caso das instituições bancárias e financeiras. A defesa do consumidor possui respaldo na Constituição Federal que a elevou à categoria de princípio geral da atividade econômica (art. 170, inc. V) e garantia individual (art. $5^{\circ}$, inc. XXXII), bem como o ordenamento jurídico repugna qualquer abuso, seja no plano constitucional, comercial e trabalhista. Ao lado desse há outro argumento. O Código de Defesa do Consumidor introduziu (ou confirmou) dois princípios elementares do novo direito dos contratos, os (princípios) da boa fé e da justiça contratual.

Modernamente, o contrato não é mais visto como algo estático e individual, mas como algo dinâmico e social, necessário para o comércio jurídico e satisfação de interesses legítimos. Com essa nova perspectiva relativiza-se o princípio pacta sunt servanda e abre-se espaço para a justiça contratual, a tutela da confiança e a boa fé. O contrato, então, deve ser o instrumento de necessidades individuais e coletivas, não para a supremacia de um contratante sobre o outro ou para que esse enriqueça às custas daquele.

\footnotetext{
${ }^{8}$ MARQUES, Cláudia Lima. Boa-fé nos serviços bancários, financeiros, de crédito e securitários e o Código de Defesa do Consumidor: informação, cooperação e renegociação? , in Revista do Consumidor no 43, ano 11, julho-setembro de 2002. Editora Revista dos Tribunais, São
} 
Nesse sentido: Assim, através da aplicação dos princípios que regem a nova realidade contratual, busca-se a segurança jurídica, mas não através da liberdade contratual, onde imperava a supremacia da "palavra dada" (pacta sunt servanda), mas através da tutela da confiança e da boa fé, banhados pelo princípio da justiça contratual. Se essa é a tendência no momento e se o Código de Defesa do Consumidor contém normas que relativizam a força obrigatória do contrato, além de não representar o direito do consumidor um sistema excepcional e sim especial, resta aplicá-lo sempre que frente a frente estiverem contratantes economicamente desnivelados, não porque haja propriamente relação de consumo, mas porque todo e qualquer contrato deve ser celebrado, executado e interpretado segundo aqueles dois princípios (princípios que tem as suas regras positivadas naquele estatuto)."

Portanto, diante do entendimento uniformizado de nossa doutrina especializada e aos enunciados dos nossos Tribunais Superiores, é de ser julgada totalmente improcedente a ADIN 2591, mantendo os direitos conquistados pelos consumidores para manter um equilíbrio financeiro e contratual com as Instituições Financeiras.

\section{As Conseqüências da aplicação do Código de Defesa do Consumidor na Internet Banking}

São as seguintes:

a) proteção publicitária: as ofertas de serviços e produtos feitas nos sites bancários vinculam os bancos nos termos do art. 30 do CDC. Além disso estipulações de difícil compreensão devem ser consideradas nulas ou sofrerem uma interpretação em favor do consumidor, como falta de informações sobre serviços ofertados, falta de esclarecimento sobre os riscos da rede, cláusulas de isenção de responsabilidade civil.

b) dever de proteção e segurança: os bancos devem valer-se de mecanismos de segurança para proteger o consumidor;

c) dever de informação: nos termos do CDC, art. $6^{\circ}$, inc I, o consumidor deve ser esclarecido sobre exatamente o que está contratando, quais os preços, quais as tarifas cobradas das operações eletrônicas, etc. Deve o cliente ser informado, inclusive, se o banco está monitorando a navegação do consumidor por meio de cookies ${ }^{9}$.

Paulo - SP.

${ }^{9}$ TIMM, Luciano Benetti. A prestação de serviços bancários via Internet (home banking) e a proteção ao consumidor. In Revista de Direito do Consumidor $\mathrm{n}^{\circ} 38$. 


\section{A operação dos bancos na Internet}

Para operar na Internet é necessário que os bancos tenham:
a) um servidor (próprio ou de terceiro);
b) um website (constituído por webpages);
c) um endereço;
d) links e
e) protocolos de segurança.

a) O servidor é um supercomputador que fará a ligação do banco com a rede mundial de computadores e, portanto, com os microcomputadores dos consumidores, os quais, por sua vez, também estarão ligados na rede por meio de um servidor. O banco pode ter o seu próprio servidor ou pode valer-se de um terceiro, o que normalmente é chamado de outsourcing ou terceirização.

b) O website são o conjunto de informações eletrônicas armazenadas em um tipo especial de computador (servidor), mediante um programa de computador inserido naquele servidor, em linguagem http (Hypertext Transfer Protocol), que serão transportadas pelas linhas telefônicas ou cabos até os microcomputadores e depois lidas e decodificadas para imagens, textos, músicas pelos navegadores ou browsers (softwares como o netscape e o explorer). É isto que tornará o serviço bancário mais atrativo e operacional ao consumidor, pois a tele apresenta-se colorida, fácil, etc. O website é constituído por webpages (programas) e que trarão na tela do computador do consumidor os passos para a operacionalização da contratação do serviço bancário de uma forma eficiente e atraente, além de que cada página tem o seu endereço eletrônico.

c) O endereço eletrônico é a localização do website no servidor e permitirá ao consumidor encontrar a "sede” do banco na Internet (URL). Consiste em:

1) protocolo: http

2) nome: www + nome de domínio secundário (identificador do banco) + nome de domínio privado (atividade a que se destina, naturalmente comercial), ex: www.citibank.com.br 
3) localização do arquivo: www.citibank.com.br/seguros

d) links, que são dispositivos que permitirão ao consumidor navegar na internet e na própria webpage do banco de maneira ágil e fácil sem necessidade de digitar os endereços eletrônicos das páginas, sendo instantaneamente transportado para a operação que deseja.

e) protocolos de segurança, que é fundamental para o banco para poder convencer o consumidor quão seguro é o site e a contratação de serviços pela rede ${ }^{10}$.

Com o dito, os bancos estarão aptos para ficarem acessíveis 24 horas por dia, no país todo e no mundo, vendendo seus produtos e serviços

\subsection{O consumidor na Internet}

Para que o consumidor possa contratar serviços bancários é necessário: a) um computador pessoal , b) um modem, c) uma linha telefônica (ou outro modo de transmissão de dados como os cabos de TV) para a conseguir a interligação com o servidor, d) um provedor e e) um navegador.

a) o modem é um hardware que transforma informações digitalizadas em dados analógicos para transitarem na rede telefônica e chegarem ao servidor;

b) a linha telefônica é a interligação do computador do consumidor com o servidor.

c) o provedor interliga o computador do consumidor na rede mundial de computadores e conseqüentemente com o site dos bancos, estabelecendo uma conexão on líne . Por meio disso, o consumidor terá acesso às ofertas de serviços e produtos bancários;

d) o browser ou navegador é o software decodificador das informações recebidas do website do banco e que fica instalado no hard disk do computador do consumidor. Assim, ele lerá os programas constantes do servidor em que está hospedado site do banco e os transformará em textos, mensagens, cores, som na tela do computador do consumidor (e que permitirá o download de informações diversas.

\footnotetext{
${ }^{10}$ MARQUES, Cláudia Lima. Sociedade de informação e serviços bancários. In Revista de Direito do Consumidor no 39 , julho - setembro de 2001.
} 


\section{Jurisprudência}

\section{RESPONSABILIDADE CIVIL. RETIRADAS DE CADERNETA DE POUPANÇA POR PESSOA NÃO IDENTIFICADA. APLICAÇÃO DO CÓDIGO DE DEFESA DO CONSUMIDOR ÀS OPERAÇÕES BANCÁRIAS. DANOS MATERIAL E MORAL CONFIGURADOS. INDENIZAÇÃO DEVIDA.}

AC 2002.38.00.007826-5/MG

Relatora: Desembargadora Federal Selene Maria de Almeida

Julgamento: 31/03/2003

A presente apelação visa à reforma da sentença que condenou a Caixa Econômica Federal em danos morais e materiais, decorrentes da ocorrência de dois saques na caderneta de poupança da apelada, por pessoa não-identificada.

Alega, a apelante, a ausência de responsabilidade no evento, a inexistência de dano moral e a inaplicabilidade do Código de Defesa do Consumidor aos contratos bancários.

Consoante entendimento da melhor doutrina e precedentes jurisprudenciais do egrégio STJ, não há como negar a aplicação das regras protetoras do CDC à atividade bancária e suas operações.

Ainda que os elementos dos autos não fossem suficientes à conclusão de que não houve a concorrência da apelada para a retirada dos valores da conta de poupança, não é razoável exigirse da poupadora a prova de que não fez mal uso do cartão magnético e senha pessoal, cabendo, ao contrário, exigir-se da instituição bancária a prova de que seu sistema é seguro e inviolável. Inteligência do art. 14, § $1^{\circ}$ do CDC.

Dano moral consistente no abalo sofrido pela apelada em sua tranqüilidade, bem como nos transtornos experimentados na busca de recomposição do seu patrimônio. Devida indenização por danos materiais, equivalente ao prejuízo do capital suportado, e dano moral no valor de $\mathrm{R} \$$ $2.000,00$.

A Turma, à unanimidade, negou provimento à apelação.

2. Tribunal de Justiça do RS

Comarca de origem: Canoas

AC: 70008485500

Relator: Carlos Eduardo Zietlow Duro

Data do julgamento: 06/05/2004

2. EMENTA: NEGÓCIOS JURÍDICOS BANCÁRIOS. RESPONSABILIDADE CIVIL. OPERAÇÕES VIA INTERNET CONTESTADAS PELO CORRENTISTA. FALHA NA 
PRESTAÇÃO DO SERVIÇO. CARACTERIZAÇÃO. ESTORNO DOS VALORES EM PRAZO RAZOÁVEL PELO DEMANDADO. DANOS MORAIS. NÃO-CONFIGURAÇÃO. Restando incontroverso que as operações noticiadas à inicial, efetuadas via Internet, não foram de responsabilidade do demandante, caracterizada a falha na prestação do serviço pelo banco demandado. Aplicação do art. 14 do CDC. Descabimento da condenação por danos morais, tendo em vista a ausência de qualquer prova no sentido de que o demandado tenha se negado a fazer a devolução do numerário, causando transtornos ao autor, tendo, inclusive, efetuado o estorno dos valores em prazo razoável, bem como inexistente comprovação de que tenha o autor sofrido prejuízos em decorrência do evento. Eventuais transtornos são normais e aceitáveis em casos como o dos autos, uma vez que o banco necessita de prazo razoável para verificar se houve operação irregular, inclusive com eventual conluio do demandante, para deferir o ressarcimento. PREQUESTIONAMENTO. A apresentação de questões para fins de prequestionamento não induz à resposta de todos os artigos referidos pela parte, mormente porque foram analisadas todas as questões entendidas pertinentes para solucionar a controvérsia posta na apelação. Apelação do autor desprovida. Apelação do réu provida. (APELAÇÃO CÍVEL No 70008485500, DÉCIMA SEGUNDA CÂMARA CÍVEL, TRIBUNAL DE JUSTIÇA DO RS, RELATOR: CARLOS EDUARDO ZIETLOW DURO, JULGADO EM 06/05/2004)

\section{Tribunal de Justiça do RS \\ Comarca de origem: Canoas \\ AC: 70004602314 \\ Relator: Nereu José Giacomolli \\ Data do julgamento: 15/102003}

3. EMENTA: RESPONSABILIDADE CIVIL. DANOS MORAIS. COMPRA E VENDA DE TELELFONE CELULAR NÃO CONCRETIZADA. SOLICITAÇÃO DE ABERTURA DE CRÉDITO JUNTO À FININVEST S/A ATRAVÉS DA INTERNET. FALHA NO CANCELAMENTO DA OPERAÇÃO. CADASTRAMENTO JUNTO AOS BANCOS DE INADIMPLENTES DO CONSUMIDOR QUE NÃO REALIZAOU O NEGÓCIO DE COMPRA E VENDA. RESPONSABILIDADE SOLIDÁRIA ENTRE A LOJA REVENDEDORA DE APARELHOS CELULARES E FININVEST S/A HAJA VISTA QUE NÃO FICOU DEMONSTRADO QUE A REVENDEDORA EFETIVAMENTE NÃO CONTRIBUIU NA RELAÇÃO CAUSAL PARA O CADASTRAMENTO DO AUTOR. PEDIDO DE MAJORAÇÃO DA VERBA INDENIZATÓRIA. 1 - Não demonstrada a ausência de contribuição na relação causal entre a ação e o resultado danoso, a loja revendedora de celulares deve responder pelo ilícito. 2 - O valor do dano moral deve ser fixado com base nos critérios do bom senso e da razoabilidade, considerando o duplo aspecto, de compensar a vítima e punir o ofensor, adequado ao caso concreto. 3 ¿ Verba indenizatória arbitrada pelo magistrado de primeiro grau mantida. PRELIMINARES REJEITADAS. RECURSO DO AUTOR PARCIALMENTE PROVIDO E DESPROVIMENTO DOS DEMAIS. (APELAÇÃO CÍVEL N ${ }^{\circ}$ 70004602314, NONA CÂMARA CÍVEL, TRIBUNAL DE JUSTIÇA DO RS, RELATOR: NEREU JOSÉ GIACOMOLLI, JULGADO EM 15/10/2003) 


\section{A Internet Banking na América Latina}

\subsection{México}

No México existe o artigo 52 da "Ley de Instituciones de Crédito", que coloca a possibilidade do Home Banking ou Internet Banking, porém não existe um regulamento específico respeito às condições operantes neste contexto, pois estas são determinadas por cada banco.

Apesar disso, o portal da Comissão Nacional para a Proteção dos Usuários de Serviços Financeiros apresenta um parágrafo onde menciona dentre outras considerações e recomendações pertinentes:

"Las modificaciones efectuadas al Código de Comercio y al Código Civil Federal, resultan aplicables a este tipo de operaciones electrónicas, una comunicación de esta clase tiene fuerza probatoria, siempre y cuando la información sea generada o comunicada en forma íntegra, lo cuál solo puede realizar la institución financiera y no el usuario, pues no existe forma indubitable en la que el usuario pueda presentar a una autoridad la información generada vía Internet, ya que el único recurso con que cuenta sería almacenar en medios electrónicos la información generada y, una vez separada de la fuente, ésta pierde el carácter probatorio.

Por lo anterior, para saber a qué atenerse, y evitarse sorpresas, pregunte directamente a la institución financiera que ofrece los servicios, todas las dudas que tenga. A continuación se mencionan algunos aspectos respecto de los cuales es conveniente que usted tenga una respuesta"

A seguir, o artigo 52 da Lei de Instituições de Crédito referido anteriormente:

ARTICULO 52.- Las instituciones de crédito podrán pactar la celebración de sus operaciones y la prestación de servicios con el público, mediante el uso de equipos, medios electrónicos, ópticos o de cualquier otra tecnología, sistemas automatizados de procesamiento de datos y redes de telecomunicaciones, ya sean privados o públicos, estableciendo en los contratos respectivos las bases para determinar lo siguiente:

\section{Las operaciones y servicios cuya prestación se pacte;}

II. Los medios de identificación del usuario y las responsabilidades correspondientes a su uso, y

III. Los medios por los que se haga constar la creación, transmisión, modificación o extinción de derechos y obligaciones inherentes a las operaciones y servicios de que se trate. 
O uso dos meios de identificação que sejam estabelecidos conforme o previsto neste artigo, em substituição da assinatura autógrafa, produzirá os mesmo efeitos que as leis outorgam aos documentos correspondentes e, conseqüentemente, terão o mesmo valor probatório.

A instalação e o uso dos equipamentos e meios indicados no primeiro parágrafo deste artigo, sujeitar-se-ão às regras de caráter geral que em seu caso emita a Comissão Nacional Bancária e de Valores.

\subsection{Venezuela}

Na Venezuela a situação é semelhante à mexicana, na "Ley de Bancos y Otras Instituciones Financieras”, cuja última reforma foi em 2001, prevê que a prestação de serviços bancários virtuais em sua seção terceira, os artigos mais importantes, que são os 70, 71 e 73, sendo os seguintes:

\section{De los Servicios Desmaterializados}

Articulo 70. Los servicios al público que presten los bancos, entidades de ahorro y préstamo, y demás instituciones financieras, a través de medios en los cuales el soporte documental se encuentre desmaterializado, deberán cumplir con la normativa prudencial que dicte la Superintendencia de Bancos y Otras Instituciones Financieras, y las leyes especiales que regulen la materia.

\section{De la Banca Virtual}

Artículo 71. Los bancos, entidades de ahorro y préstamo y demás instituciones financieras, que aspiren operar dentro del Sistema Bancario Nacional bajo la modalidad de banca virtual, deberán estar debidamente autorizados por la Superintendencia de Bancos y Otras Instituciones Financieras. Dicho servicio, será regulado conforme a la normativa que al efecto dicte la Superintendencia de Bancos y Otras Instituciones Financieras.

\section{De los Servicios Financieros Virtuales}

Artículo 72. A los efectos de el presente Decreto Ley, se entiende por servicios financieros prestados a través de banca virtual, al conjunto de productos y servicios ofrecidos por los bancos, 
entidades de ahorro y préstamo y demás instituciones financieras, para realizar, por medios electrónicos, magnéticos o mecanismos similares, de manera directa y en tiempo real las operaciones que tradicionalmente suponen la realización de llamadas telefónicas o movilizaciones de los usuarios a las oficinas, sucursales o agencias de la institución.

\section{Prohibición}

Artículo 73. Los bancos, entidades de ahorro y préstamo y demás instituciones financieras no podrán prestar ni ofrecer, a través de la banca virtual, productos o servicios distintos a los contemplados en este Decreto Ley, o autorizados por la Superintendencia de Bancos y Otras Instituciones

Financieras.

\subsection{Panamá}

No Panamá aprovou-se o Acuerdo 5-2003 da Superintendência de Bancos de 12 de julho de 2003, no qual são estabelecidas as diretrizes básicas relacionadas com o exercício dos serviços do Internet Banking. O mesmo diz em seu artigo $9^{\circ}$ a obrigação que têm os bancos de manter controles mínimos de segurança, com o intuito de garantir a autenticidade, integridade, sigilo e não renúncia da informação. Também obriga aos provedores do serviço de "Banca Electrónica" ou Internet Banking a tomar as previdências pertinentes para cumprir com os controles de segurança estabelecidos pelo banco em função desta regulamentação.

Conforme o supracitado o uso deste serviço gera riscos de operação, considerando a segurança e sigilo da informação financeira que pode afetar tanto o cliente quanto o banco e o risco legal, pois são poucos os países que possuem legislação vigente sobre o tema, surgindo dúvidas sobre a validade do contrato pelo fato de ser eletrônico, proteção de dados pessoais, conflitos de competência, dentre outros.

Neste país da América Central não existe uma lei regulamentando todos os aspectos do Internet Banking. Porém, naquilo considerado no “Acuerdo 5-2003” menciona-se a lei de documentos e assinaturas eletrônicas de 2001, a qual esclarece a dúvida sobre a validade do contrato de E-Banking e assinatura eletrônica, dizendo que os contratos celebrados por meio de 
documento eletrônico serão válidos da mesma maneira e produzirão os mesmo efeitos que os celebrados por escrito em documentos feitos em papel comum ${ }^{11}$.

\section{A Internet Banking na Europa}

\subsection{Na União Européia}

Na Europa, entende-se que, pelo fato da Internet ser única, os pagamentos têm características próprias, porém, apesar disso existem pontos discordantes no mundo físico, pois sempre haverá que ter em conta o fato das partes estarem longe uma das outras.

Segundo a Comissão das Comunidades Européias, o pagamento eletrônico é aquela operação de pagamento, realizada com um cartão magnético ou com um microprocessador incorporado num terminal de pagamento eletrônico ou terminal de ponto de venda.

Esta definição parece ser pobre, por esta razão pode entende-se como pagamento eletrônico aquele mecanismo pelo qual é executado a contraprestação de uma obrigação assumida mediante a Internet, ou seja, por meio da contratação eletrônica.

Portanto, considerando o pagamento eletrônico só em dinheiro e sendo a Internet um sistema caracterizado pela falta de presença física de ambas as partes, o dinheiro não poderá ser entregue fisicamente, por isto haverá que recorrer-se a outros meios de entrega deste. Surgindo desta forma os pagamentos à distância e dentro deles do dinheiro eletrônico.

O dinheiro eletrônico constitui um substituto do dinheiro comum e é definido legalmente no ordenamento jurídico conforme o artigo $1^{\circ}$ da Diretiva 2001/46/CE como um valor monetário representado por um crédito exigível ao seu emissor: armazenado num suporte eletrônico; emitido ao receber fundos de um importe cujo valor não será inferior ao valor monetário emitido; aceito como meio de pagamento por empresas diferentes do emissor.

\footnotetext{
${ }^{11}$ www.alfa-redi.org/revista/data/66-6.asp
} 
Para a sua utilização é armazenado num suporte eletrônico, dando lugar à existência de dois tipos de suportes diferentes, que são o cartão inteligente ou magnético e a memória do computador (dinheiro na rede) ${ }^{12}$.

\subsubsection{Meios de pagamento}

O desenvolvimento da tecnologia e a rápida evolução do comércio eletrônico impulsou a criação de novos sistemas de pagamentos, para facilitar e outorgar maior confiança aos usuários nas transações monetárias que são realizadas na rede, impulsionando desta forma os negócios virtuais e o desenvolvimento da nova economia.

A Recomendação 1997/489 faz distinção entre instrumentos de pagamento mediante acesso à distância e instrumentos de moeda eletrônica.

A primeira categoria compreende as formas ordinárias de pagamento conhecidas por todos até agora (remessa bancária, conta corrente, etc). São os clássicos procedimentos tradicionais, que garantem um alto grau de segurança, mas, por outro lado, têm pequenas desvantagens, como podem ser a velocidade e a imediatidade das transações.

Na segunda classificação, têm cabimento os meios de pagamento que permitem uma conexão imediata.

A Diretiva 2004/46/CE considera o dinheiro eletrônico como um substituto eletrônico das moedas e das notas de banco, pensado para realizar pagamentos eletrônicos de quantia limitada. O dinheiro eletrônico, como outro meio de pagamento, nasce para facilitar as operações financeiras e as transações monetárias na rede e fora da rede, assim como para evitar os inconvenientes que apresenta o pagamento eletrônico mediante o cartão de crédito/débito.

\footnotetext{
${ }^{12}$ ASENSIO, Pedro Alberto de Miguel. Derecho Privado de Internet. Editora Civitas, Madri - Espanha, 2000 


\subsubsection{Instrumentos de pagamento à distância.}

Segundo a Recomendação 97/487/CE do Parlamento Europeu, considera-se instrumento de pagamento à distância àquele instrumento que permitir ao seu titular aceder aos fundos de sua conta numa entidade, pelo qual seja autorizado o pagamento a um beneficiário, operação que normalmente exige um código de identificação pessoal ou qualquer outra prova similar de identidade, ficando incluídas em particular os cartões de pagamento (cartões de crédito, de débito, etc) e os serviços de tele-banco e de banco a domicílio.

São meios de pagamento que normalmente têm começo on line, pois o usuário elege o meio de pagamento na rede, mas são formalizadas off line. São os meios de pagamento tradicionais, como são os pagamentos em conta, transferências a conta e pagamentos diversos.

Apesar do citado supra a própria Comissão Européia declarou que o comércio eletrônico não poderá desenvolver-se sem sistema de pagamento eletrônico de confiança, fáceis de utilizar, eficientes e seguros, para tal, começaram-se a traçar as diretrizes do futuro desenvolvimento dos pagamentos eletrônicos e do comércio eletrônico em geral.

A COM 353/97, com o lema “aumentar a confiança dos consumidores nos instrumentos de pagamento eletrônico telemático no mercado único”, diz que um conjunto de condições mínimas que devem ser respeitadas nas operações de pagamento eletrônico, com o intuito de garantir a segurança dos consumidores finais. $\mathrm{O}$ art. 3, especificamente, dispõe que o emissor de um instrumento de pagamento eletrônico, antes da conclusão do contrato, está obrigado a comunicar ao titular as modalidades e condições contratuais relativas à emissão ou ao uso de tal instrumento.

As condições devem de conter como mínimo:

Uma descrição do instrumento de pagamento eletrônico; 
Uma descrição das obrigações e das responsabilidades do titular e do emissor;

O prazo dentro do qual deve ser efetuado o débito sobre a conta do titular, ou seja, o período de tempo no qual será emitida a fatura;

O tipo de despesas impostas ao titular (desde o importe das tarifas, as despesas de comissão, até o tipo de juros);

O fim dentro do qual uma operação poderá ser reclamada por parte do titular.

A Diretiva 2000/12/CE aplica-se às instituições de moeda eletrônica e pretende introduzir um regime especial de vigilância para estas entidades. Esta diretiva cria um quadro jurídico neutro, do ponto de vista tecnológico, que harmoniza a vigilância destes órgãos para assegurar o correto desenvolvimento e integridade financeira. Estes institutos devem de garantir uma gestão sã e prudente, seja de suas atividades como dos procedimentos administrativos e contábeis e adequados mecanismos de controle.

A diretiva direciona-se a alcançar um equilíbrio entre a exigência de prever disposições finalizadas tanto para assegurar a integridade financeira dos institutos de moeda eletrônica, como a proteção dos consumidores, e a exigência de garantir que o desenvolvimento dos esquemas de dinheiro virtual não se veja obstaculizado por um excesso de regulamentação. Mesmo assim, está sendo vista uma cooperação na adoção de diferentes instrumentos de moeda eletrônica para evitar que sua introdução possa danificar a estabilidade do sistema financeiro.

As Diretivas 2000/28/CE e 2004/46/CE sobre moeda eletrônica estabelecem que só os institutos submetidos à vigilância, que cumprirem determinadas condições normativas e financeiras e que possam garantir a segurança técnica, poderão emitir este tipo de moeda.

Tais disposições foram repassadas de modo idêntico ao da Recomendação da Comissão 489/97 relativa às operações que se efetuam mediante instrumentos de pagamento eletrônico, com especial referência às relações entre os emissores e os titulares destes instrumentos. Abrange também as normas sobre a responsabilidade no caso de transações não autorizadas e sobre a transferência eletrônica de fundos, também para o "banco a domicílio”(home banking). 
Sobre a mesma matéria encontra-se a COM 2001/11, que surgiu com a intenção de prevenir o fraude e as falsificações nos meios de pagamento.

Existe uma significativa importância na comunicação da Comissão direcionada ao Conselho e ao Parlamento Europeu sobre o “comércio eletrônico e os serviços financeiros”, COM 2001/66 do 7 de fevereiro de 2001, que examina as medidas necessárias para o desenvolvimento do comércio eletrônico e dos serviços financeiros, para terminar com a fragmentação do mercado destes serviços e para estimular a confiança dos consumidores. Com este intuito a Comissão projetou três áreas de intervenção:

Neste mesmo caminho encontra-se a resolução do Parlamento Europeu em 4 de outubro de 2001 sobre a Comunicação 2001/66. Tendo em conta a finalização do prazo para a recepção da Diretiva sobre o comércio eletrônico, a Instituição comunitária quis precisar alguns peculiares aspectos que são referentes aos serviços financeiros. A finalidade é assegurar a uniformidade de tratamento dos consumidores no interior da União Européia, contribuindo ao mesmo tempo para aumentar a confiança dos mesmos no comércio eletrônico. Especificamente, o ato ressalta a importância de dar vida a uma área única para os pagamentos onde são realizadas as transferências de fundos além das fronteiras para que seja igual de fácil e pouco dispendioso como já é no interior dos países.

Sob este perfil, o Parlamento expressou a sua aprovação à Comissão por haver reconhecido este importante aspecto na proposta sobre os pagamentos seguros mediante a Internet. Também intensificaram-se as ações para animar o setor dos serviços financeiros para que adotem um código europeu de conduta para a utilização de uma linguagem clara com os consumidores.

Do mesmo jeito, pede aos Estados membros e às partes interessadas que contribuam na iniciativa da Comissão para a criação de uma Rede Extrajudicial Européia (EEJ - NET) e de uma Rede para as reclamações (FIN - NET). Tudo isso com o objetivo de facilitar aos consumidores a obtenção de indenizações transfronteiriças. 
A proposta da Diretiva do Parlamento Europeu e do Conselho COM 98/461, que modifica a Diretiva 77/780, que trata da coordenação das disposições legislativas, regulamentares e administrativas a que se referem ao acesso à atividade, por parte dos entes de crédito e de seu exercício, estende a noção “entes de crédito”, fazendo-os entrar na categoria, também aos institutos de moeda eletrônica.

O objetivo disso é evitar distorções da competência entre emissores de moeda eletrônica, submetendo-os, portanto, às distorções comunitárias relativas ao exercício do crédito e tendo em conta as suas particulares características ${ }^{13}$.

\subsection{Espanha}

O quadro normativo dos meios de pagamento eletrônicos no ordenamento jurídico neste país é praticamente inexistente, se bem que ocorre o mesmo com outros meios de pagamento que podendo ser considerados como tradicionais, por exemplo, os cartões de crédito e débito que são usados para a realização de pagamentos na Internet. Por esta razão está em elaboração a Lei Financeira e a Lei sobre transações efetuadas mediante cartões como instrumentos eletrônicos de pagamento, que nascem com a vontade de adaptar-se à normativa européia reguladora deste tipo de elementos e também para garantir legalmente a um conjunto de aspectos muito ignorados até agora.

Especial referência é feita ao Anteprojeto de Lei Financeira que regulamenta, em seu artigo 19, dentro do capítulo correspondente à inovação tecnológica, os meios de pagamento mediante a Internet.

Transpondo desta maneira ao ordenamento jurídico a Diretiva 200/46/CE sobre o acesso à atividade das entidades de dinheiro eletrônico e seu exercício assim como a supervisão de tais entidades.

\footnotetext{
${ }^{13}$ www.curia.eu.int
} 
Sem prejuízo das regulamentações específicas que possam surgir para regulamentar determinados meios de pagamento, existem outras normas que também seriam de aplicação, como é o caso da Lei 19/1985, de 16 de julho, "Lei cambiária e cheque”14.

\subsection{Itália}

Não existe atualmente uma normativa italiana específica em matéria de instrumentos de pagamento eletrônico. Porém, um conjunto de fontes normativas indicam alguns dos objetivos prioritários a serem perseguidos e que especificam os instrumentos finalizados a garantir uma maior segurança nas transações por meio da Internet. Uma definição de "pagamento eletrônico ou telemático” pode ser encontrado no DPR 513/97, art. 14, onde é definido como: “quaisquer transferência eletrônica de dinheiro realizada entre sujeitos privados, Administrações Públicas, e entre estas e sujeitos privados, conforme as regulamentações técnicas definidas pelo sucessivo Decreto do Presidente do Conselho de Ministros em 8 de fevereiro de 1999, o qual, estabelecendo as regras para a formação, transmissão, conservação, duplicação, reprodução e validade dos documentos eletrônicos. Pretende garantir a integridade, disponibilidade e sigilo da informação contida no documento, também no referente ao uso de chaves biométricas, ou seja, aquelas seqüências de códigos informáticos usados no âmbito de mecanismos de segurança, direcionados a verificar a identidade pessoal do usuário com base em específicas características físicas.

O DPR 318/99, que introduz as normas encaminhadas à individualização das medidas mínimas de segurança pra o tratamento dos dados pessoais, (nos termos do art. 15 da Lei 675/96) representa um passo importante referente às garantias proporcionadas nas transações comerciais mediante a Internet. Conforme com o previsto no art. $3^{\circ}$ (elaborações acessíveis mediante uma rede de telecomunicações disponíveis para o público), o uso empresarial da rede deve de estar sujeito ao máximo das medidas de segurança. Além disso, considerando o desenvolvimento dinâmico de Internet, todas as inovações deverão ser controladas com freqüentes verificações. No comércio eletrônico deve considerar-se duas disposições introduzidas pela lei 675/96, que

\footnotetext{
${ }^{14}$ www.bde.es
} 
colocam um conjunto de complicações na liberdade do uso da rede: o art. $6^{\circ}$, que regulamenta o tratamento dos dados retidos no estrangeiro, e o art. 28, relativo à transferência de dados ao exterior. A adoção de medidas adequadas à natureza dos dados ou dos serviços e às probabilidades de inconvenientes técnicos constitui um dos instrumentos essenciais ao objetivo de favorecer esta “cultura da segurança”, que permita um nível sempre mais elevado de proteção das transações eletrônicas e dos correspondentes instrumentos de segurança. O uso de idôneos instrumentos de segurança comporta, como resultado, um aumento da confiança do consumidor e de outros operadores econômicos, favorecendo a multiplicação das transações na Internet.

Para tal propósito o D. L 114/98, que reformula a disciplina relativa ao setor do comércio, em seu art. 21, especifica que, o Ministério da Indústria, Comércio e Artesanato é competente para promover a introdução e o uso do comércio eletrônico mediante ações voltadas a favorecer o uso de instrumentos e técnicas de gestão de qualidade, direcionadas a garantir a confiabilidade dos operadores e incrementar a confiança do consumidor ${ }^{15}$.

\section{CONCLUSÃO}

As operações bancárias via Internet, são as mesmas operações feitas antigamente, mas atualmente feitas de modo mais rápido, claro que os nossos legisladores, os juízes e os doutrinadores estão encarregando-se dos ajustes necessários para que a informática, com suas características próprias, não compliquem o trabalho dos operadores do Direito.

O Código de Defesa do Consumidor entrou como meio para que os consumidores possam ser defendidos, se bem que os bancos não gostaram, pois impediu os abusos que faziam e que de vez em quando fazem, os entendimentos do Superior Tribunal de Justiça e do Supremo Tribunal Federal, além dos Tribunais de Justiça continuam dando decisões em favor do consumidor quando é lesado.

\footnotetext{
${ }^{15}$ www.interlex.it
} 
O Internet Banking está ajudando muito num melhor serviço bancário, mas que justamente o fato de fazer contratos entre pessoas que não se vêem tira um pouco a credibilidade em determinados casos, então para isso os bancos têm que continuar investindo na tecnologia da segurança eletrônica, inclusive na parte física das agências e evitar assaltos e apropriações indébitas na rede, dor de cabeça para muitas entidades financeiras obrigando-as a pagar indenizações que poderiam ser evitadas.

No âmbito do Direito Comparado o Brasil fica à frente de vários países latino-americanos, pois é o único em ter um Código de Defesa do Consumidor, pois nestes só existem leis que não chegam a ter muita força como no nosso país, e também a legislação brasileira não fica atrás das leis e diretivas européias, apesar da Europa estar mais desenvolvida tecnologicamente.

\section{REFERÊNCIAS}

ALFA-REDI. [Home page]. Bogotá, 2005. Disponível em: <www.alfa-redi.org>.

ASENSIO, Pedro Alberto de Miguel. Derecho privado de internet. Espanha: Civitas, 2000.

BANCO DE ESPAÑA. [Home page]. Madrid, 2005. Disponível em: <www.bde.es>.

BRASIL. Superior Tribunal de Justiça. [Home page]. Brasília, 2005. Disponível:

$<$ www.stj.gov.br>.

CVRIA. [Home page]. [S.l], 2005. Disponível em: <www.curia.eu.int>.

E-BIT INFORMA. [S.l.]: E-BIT, 2003- . Disponível em: <www.ebitempresa.com.br/ index_ebitinforma.htm>.

FEDERAÇÃO BRASILEIRA DOS BANCOS. [Home page]. São Paulo, 2005. Disponível em: $<$ www.febraban.org.br>. 
GOMES, Alessandra Aparecida Calvoso. Operações bancárias via internet (internet banking) no Brasil e suas repercussões jurídicas. Revista dos Tribunais, São Paulo, v. 816, out. 2003.

INTERLEX. [Home page]. São Paulo, 2005. Disponível: <www.interlex.it> .

MARQUES, Cláudia Lima. Boa-fé nos serviços bancários, financeiros, de crédito e securitários e o código de defesa do consumidor: informação, cooperação e renegociação. Revista do Consumidor, São Paulo, v. 11, n. 43, jul./set. 2002.

Sociedade de informação e serviços bancários. Revista de Direito do Consumidor, São Paulo, v. 10, n. 39, p. 49-74, jul./set. 2001.

REVISTA ELECTRÓNICA DE DERECHO INFORMATICO. [S.l: s.n.], 2005. Disponível em: $<$ www.derecho.org/redi $>$.

RIO GRANDE DO SUL. Tribunal de Justiça do Estado do Rio Grande do Sul. [Home page]. Porto Alegre, 2005. Disponível: <www.tj.rs.gov.br>.

SANTANDER. [Home page]. São Paulo, 2005. Disponível: <www.santander.com.br>.

TIMM, Luciano Benetti. A prestação de serviços bancários via Internet (home banking) e a proteção ao consumidor. Revista de Direito do Consumidor, São Paulo, v. 10, n. 38. p. 74-92, abr./jun. 2001. 